\title{
PKM PELATIHAN ONLINE-BASED LEARNING ASSESSMENT PADA GURU MADRASAH ISLAM SWASTA AL JAMIATUL IKHLAS KECAMATAN DATUK BANDAR KOTA TANJUNGBALAI
}

\author{
Aprilza Aswani ${ }^{*}{ }^{*}$, Gabriel Ardi Hutagalung ${ }^{2}$, Winda Syafitri ${ }^{3}$ \\ 1,2,3]urusan Teknik Komputer dan Informatika, Politeknik Negeri Medan, 20155 Medan, Indonesia \\ e-mail : aprilzaaswani@polmed.ac.id ${ }^{1}$, gabrielhutagalung@polmed.ac.id ${ }^{2}$, \\ windasyafitri@polmed.ac.id ${ }^{3}$
}

\begin{abstract}
Abstrak: Wabah Covid-19 yang melanda dunia telah memaksa pembelajaran di Indonesia dialihkan ke metode daring atau online. Dalam pembelajaran, evaluasi menjadi salah satu langkah untuk menentukan keberhasilan siswa dalam belajar. Salah satu aplikasi yang dapat digunakan secara gratis untuk membantu guru dalam membuat kuis dan survei online adalah Google Form dan Quizizz. Mitra yang terlibat dalam program ini adalah guru-guru di Madrasah Islam Swasta Al Jamiatul Ikhlas Kecamatan Datuk Bandar Kota Tanjungbalai dimana persoalan utama yang dialami mitra adalah kurangnya pengetahuan dalam penggunaan IT dalam memberikan evaluasi pembelajaran kepada siswa. Oleh karena itu, solusi yang ditawarkan adalah memberikan pelatihan online-based learning assessment untuk meningkatkan pengetahuan dan keterampilan para guru tentang pembuatan, penggunaan serta optimaliasi pengunaan google forms dan quizizz sebagai media eveluasi pembelajaran. Program ini terdiri dari tahapan persiapan, pelaksanaan, monitoring, dan evaluasi. Dalam pelaksanaan pengabdian ini, tim menerapkan metode in-house training. Evaluasi kegiatan ini dilakukan setelah program selesai dilaksanakan. Target utama pasca kegiatan pengabdian ini adalah bertambahnya pengetahuan guru-guru di sekolah mitra tentang pemanfaatan E-Learning dan onlinebased learning assessment melalui penggunaan google form dan quizizz dalam mendukung program Merdeka Belajar.
\end{abstract}

Kata Kunci: PKM, MIS Al-Jamiatul Ikhlas, Google Form dan Quizizz

\begin{abstract}
The Covid-19 outbreak hitting the world has changed the learning process in Indonesia from face-to-face method to online method. In teaching and learning process, evaluation is one of the steps to determine student's achievement. There are two free applications that can be used to assist teachers in creating online quizzes and surveys; they are Google Forms and Quizizz. The target of this community service is the teachers at Madrasah Islam Swasta A/ Jamiatul Ikhlas, Datuk Bandar District, Tanjungbalai City. The main problem experienced by them is the lack of knowledge in using IT in providing class evaluations to students. Therefore, the solution offered is to provide onlinebased learning assessment training to improve the knowledge and skills of teachers regarding the creation, use and optimization of the use of Google Forms and Quizizz as evaluation tool. This program consists of stages of preparation, implementation, monitoring, and evaluation. In the implementation of this service, the team applies the in-house training method. Evaluation of this activity is carried out after the program is completed. The objective of this community serves is to increase the knowledge of teachers at target school about the use of E-Learning and online-based learning assessment through the use of Google Forms and Quizizz in supporting the Independent Learning program.
\end{abstract}

Keywords: Community Service, MIS Al-Jamiatul Ikhlas, Google Form and Quizizz 


\section{Pendahuluan}

Perkembangan ilmu pengetahuan dan teknologi dewasa ini mengalami peningkatan signifikan. Terutama dalam bidang teknologi dalam pemenuhan kebutuhan sehari-hari. Pembelajaran di era saat tidak harus bergantung pada pembelajaran konvensional. Media baru memungkinkan pembelajaran menjadi lebih aktif, inovatif, dan interaktif. Integrasi penggunaan media baru (internet) dalam proses pembelajaran sudah mulai diterapkan dalam sistem pendidikan nasional seperti ujian tulis berbasis komputer, ujian nasional berbasis komputer, dan pembelajaran berbasis daring menggunakan berbagai platform yang disediakan oleh google dan beberapa situs lainnya. Pembelajaran digital (digital learning) adalah sebuah istilah yang merepresentasikan berbagai strategi pendidikan yang disempurnakan dengan pemanfaatan teknologi (Darmaningrat et al., 2018). Proses pembelajaran meliputi pemberian material hingga pelaksanaan assessment atau evaluasi.

Adanya wabah Covid-19 di tahun 2020 di Indonesia memaksa pemerintah untuk melakukan tindakan preventif dengan meluncurkan program stay at home yang tidak terkecuali juga berpengaruh terhadap proses pembelajaran di sekolah. Pemerintah Kota Tanjungbalai juga ikut menerapkan langkah tersebut. Hal ini tentu sangat mempengaruhi proses pembelajaran sehingga himbauan untuk menggunakan platform online menjadi sebuah pilihan yang realistis. Bahkan, ujian nasional pun dibatalkan akibat dampak wabah Covid19 dan ujian kenaikan kelas pun ditiadakan. Sebagai gantinya adalah guru menggunakan nilai ujian yang berasal dari nilai harian yang diambil sebelum wabah Covid-19 dan nilai dari pembelajaran daring.

Dewasa ini Google berinovasi dalam mendukung pembelajaran dan bentuk dukungan terhadap kemajuan teknologi saaat ini (Maharani \& Kartini, 2019). Salah satu aplikasi yang dapat digunakan secara gratis untuk membantu guru dalam membuat kuis dan survei online adalah Google Form, yaitu salah satu layanan Google Docs (Batubara \& Ariany, 2016). Pemanfaatan teknologi informasi seperti Google Docs yang dipadukan dengan model-model pembinaan lain belum menjadi pilihan utama dikalangan pendidik dalam proses pembinaan. Hal ini mungkin disebabkan oleh keterbatasan perangkat yang ada di sekolah sekolah atau terbatasnya pengetahuan tentang Teknologi Informasi (TI) dikalangan guru (Dharmawan et al., 2015). Lebih lanjut, aplikasi ini dapat membantu guru untuk membuat form secara online, seperti membuat kuesioner, membuat tes pilihan ganda, atau melakukan penilaian terhadap siswanya secara realtime. Disamping google docs, ada juga situs lain yaitu quizizz yang dapat digunakan untuk melakukan evaluasi pembelajaran terhadap siswa. Hal ini juga dimungkinkan karena siswa yang berada di level SMP atau MTS saat ini dikategorikan sebagai generasi yang savvy tech yaitu yakni fasih teknologi, intens berinteraksi melalui media sosial, dan ekspresif (Wicaksono \& Rachmadyanti, 2017). Generasi net hanya perlu menggerakkan mouse di board atau hanya menyentuh screen komputer serta boleh masuk dan keluar dunia cyber tanpa harus meninggalkan rumah (Sabran \& Sabara, 2018).

Berbagai penelitian dan pengabdian masyarakat telah mengungkapkan keunggulan dari menggunakan media pembelajaran berbasis internet dengan menggunakan berbagai 
platform. Hafid et al. (2018) menyatakan bahwa penggunaan google classroom sangat disambut baik oleh guru karena mampu memberikan alternatif pembelajaran agar tidak membosankan. Pengabdian yang dilakukan oleh Ismawan et al. (2018) dengan menggunakan memanfaatkan google drive dalam pembelajaran menjadikan pembelajaran menjadi lebih menyenangkan dan nyaman. Hal ini juga dapat memicu kreatifitas guru dalam mengeksplorasi kemampuan dirinya dan siswa. Siswa juga dapat langsung melihat hasil kerja mereka dengan menggunakan editor What You See Is What You Get (Apa yang kamu lihat itulah yang kamu dapat).

Madrasah Islam Swasta Al Jamiatul Ikhlas Kecamatan Datuk Bandar Kota Tanjungbalai adalah sekolah dibawah naungan departemen agama yang terletak di Jln. Jend. Sudirman Km 5 kecamatan Datuk Bandar Kota Tanjungbalai, Sumatera Utara. Sekolah ini dipimpin oleh Ibu Nuryani Lubis, S.Pd. sebagai kepala sekolah 12 guru dan 269 siswa.. Sekolah ini memiliki 8 ruangan kelas dan 1 kantor (Admin, 2021).

Berdasarkan hasil observasi dan wawancara dengan Kepala Sekolah Madrasah Ibtidaiyah Swasta Al Jamiatul Ikhlas dapat disimpulkan bahwa guru menghadapi berbagai masalah dalam memberikan penilaian pembelajaran (assesement) kepada siswa dalam keadaan pandemic saat ini:

1. Ketidaktahuan guru dalam menggunakan google form dan quizziz karena keterbatasan pengetahuan tentang teknologi informasi.

2. Penggunaan WhatsApp tidak efektif karena tidak bisa menilai siswa secara realtime. WhatsApp digunakan untuk memberi materi tapi untuk memberikan penilaian tidak maksimal.

3. Belum adanya dukungan sekolah yang memadai dalam IT. Hanya ada 1 komputer di sekolah yang digunakan secara bergantian oleh guru.

4. Dalam mengerjakan tugas, siswa mengumpulkan tugas dengan cara memfoto hasil pekerjaaannya dan dikirimkan via pesan WA dalam grup (nomor orang tua ada di dalam grup). Masalah yang muncul adalah kualitas kamera tiap smartphone berbeda sehingga kadang gambar yang dihasilkan tidak terlalu jelas.

Guru merupakan ujung tombak dalam memajukan pendidikan di Indonesia. Kompetensi guru harus ditingkatkan di era pembelajaran digital juga mendukung program Merdeka Belajar yang dicanangkan oleh Menteri Pendidikan dan Kebudayaan Republik Indonesia. Kesiapan guru dalam menggunakan teknologi untuk menghadapi hal yang tidak terduga seperti adanya wabah penyakit perlu dilatih agar tidak mengganggu proses dan hasil pembelajaran. Selanjutnya dengan menggunakan platform digital, manfaat ekonomi yang diperoleh adalah berkurangnya penggunaan kertas sehingga ikut membantu mengurangi cost pendidikan dan ikut berpartisipasi dalam menciptakan green education.

Ini dapat disimpulkan bahwa persoalan utama yang dialami mitra adalah kurangnya pengetahuan dalam penggunaan TI dalam memberikan evaluasi pembelajaran kepada siswa. Oleh karena itu, solusi yang ditawarkan adalah memberikan pelatihan online-based learning assessment untuk meningkatkan pengetahuan dan keterampilan para guru tentang pembuatan, penggunaan serta optimaliasi pengunaan google forms dan quizizz sebagai media eveluasi pembelajaran. Hal ini dapat dilakukan karena guru telah memiliki 
smartphone serta siswa (orang tua siswa) juga memiliki smartphone. Lebih lanjut, pengetahuan tersebut dapat digunakan dalam proses belajar mengajar siswa agar pembelajaran menjadi lebih menarik dengan dipadupandakan dengan teknik pembelajaran konvensional atau off-line.

\section{Metode}

Berdasarkan hasil identifikasi permasalahan yang dihadapi mitra, kegiatan yang ditawarkan adalah memberikan pelatihan online-based learning assessment melalui penggunaan google forms via google docs dan quizizz yang dapat diakses melalui smartphone atau komputer yang telah memiliki jaringan internet sehingga nantinya para guru memiliki pengetahuan dalam mengkreasikan pembelajaran dan mampu meningkatkan kualitas pembelajaran sehingga siswa mendapatkan hasil yang maksimal. Pelatihan ini juga menjadi solusi jika terjadi keadaan darurat di masa depan seperti penyebaran wabah saat ini sehingga pembelajaran harus dilakukan secara daring kembali atau memberikan variasi dalam pembelajaran.

Dalam pelaksanaan pengabdian ini, tim menerapkan metode in-house training. Pengertian in-house training disini adalah "pelatihan" yang pelaksanaannya bertempat di sekolah mitra, tempat di mana guru-guru melaksanakan pengajaran, bekerja sama dengan tim pengabdian. Dalam pelaksanaan pelatihan, tim pengabdian akan memberikan materi mengenai e-learning dan tutorial penggunaan google forms dan quizizz. Adapun tahapan dalam kegiatan pengabdian ini adalah 1) Persiapan, 2) Pelaksanaan, 3) Monitoring, 4) Evaluasi.

\section{Hasil dan Pembahasan}

Mitra yang terlibat dalam program ini adalah Madrasah Islam Swasta Al Jamiatul Ikhlas Kecamatan Datuk Bandar Kota Tanjungbalai. Dengan permasalahan yang ada yaitu kurangnya pengetahuan dalam melakukan online-based learning assessment dengan memanfaatkan media yang tersedia. Oleh karena itu, solusi yang ditawarkan adalah memberikan pelatihan penggunaan google forms dan quizizz kepada para guru.

Lokasi pelaksanaan program ini berada sekolah mitra di Madrasah Islam Swasta Al Jamiatul Ikhlas Kecamatan Datuk Bandar Kota Tanjungbalai yang beralamat di Jln. Jend. Sudirman Km 5 kecamatan Datuk Bandar Kota Tanjungbalai, Sumatera Utara. Sesuai rencana, rincian kegiatan ini adalah sebagai berikut:

\section{Tahap Persiapan}

Tahap ini terdiri dari beberapa langkah sebagai berikut:

- Koordinasi teknis di lapangan meliputi pelaksanaan kegiatan, peserta pelatihan tempat, dan waktu pelaksanaan.

- Merumuskan permasalahan-permasalahan yang dihadapi oleh pihak sekolah (guru) dalam memberikan evaluasi kepada siswa.

- Tim pengabdian melakukan observasi kesediaan fasilitas yang mitra miliki.

- Tim pengabdian menyiapkan pelatihan, alat-alat dan bahan-bahan yang diperlukan untuk kegiatan pelatihan. 


\section{Tahap Pelaksanaan}

Dalam pelaksanaan pengabdian ini, tim menerapkan metode in-house training yang pelaksanaannya bertempat di sekolah mitra, tempat di mana guru-guru melaksanakan pengajaran, bekerja sama dengan tim pengabdian. Pada awal pelatihan, peserta diundang untuk melakukan percobaan menggunakan quizizz. Selanjutnya, tim pengabdian memberikan materi mengenai e-learning dan tutorial penggunaan google forms dan quizizz. Kemudian pelatihan ini diakhiri dengan mengundang peserta memberikan feedback lewat google form.

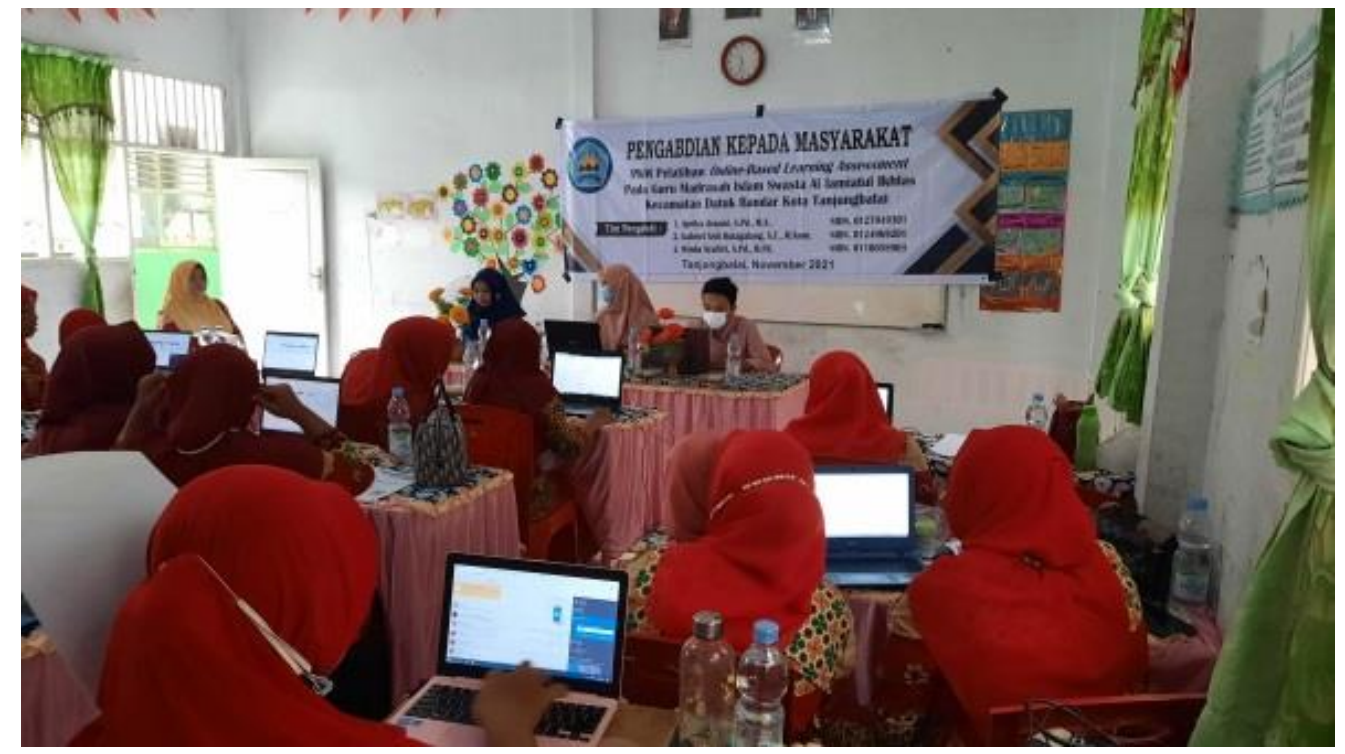

Gambar 1. Suasana Pelaksanaan PKM

\section{Tahap Monitoring}

Monitoring program dilakukan sejak awal dimulainya kegiatan ini dari tahap persiapan, proses pelaksanaan, sampai tahap akhir kegiatan. Setiap akhir tahapan kegiatan dilakukan monitoring guna mengetahui apakah pelaksanaan program sesuai dengan rencana program yang telah dibuat. Kegiatan evaluasi dilakukan berdasarkan hasil monitoring dan temuan dilapangan untuk selanjutnya dilakukan tindak lanjut melalui perbaikan.

\section{Tahap Evaluasi}

Evaluasi kegiatan ini dilakukan setelah program selesai dilaksanakan. Target utama pasca kegiatan pengabdian ini yang ingin dicapai adalah bertambahnya pengetahuan guru-guru di Madrasah Islam Swasta Al Jamiatul Ikhlas Kecamatan Datuk Bandar Kota Tanjungbalai yang beralamat di Jln. Jend. Sudirman Km 5 kecamatan Datuk Bandar Kota Tanjungbalai, Sumatera Utara tentang pemanfaatan online-based learning assessment melalui penggunaan google form dan quizizz dalam mengevaluasi hasil kerja siswa.

Pada tahap evaluasi, feedback dari para guru tentang pelatihan ini merupakan data yang sangat penting. Berikut hasil masukan dari peserta. 
1. Seluruh peserta (100\%) berpendapat bahwa materi yang diberikan bermanfaat dalam pembelajaran.

2. Seluruh peserta (100\%) berpendapat materi yang dipersiapkan dan disampaikan oleh tim lengkap, jelas dan dapat dimengerti.

3. $91 \%$ peserta menyatakan mereka mengerti cara penggunaan Quizizz dan Google Form setelah pelatihan.

4. $45.5 \%$ dari peserta menyatakan mereka akan menggunakan Quizizz dan Google form dalam pembelajaran setelah pelatihan, $54.5 \%$ dari mereka menyatakan mereka mungkin akan menggunakannya.

5. Seluruh peserta (100\%) menyatakan bahwa kegiatan ini perlu diikuti dan dilanjutkan dengan kegiatan sejenis.

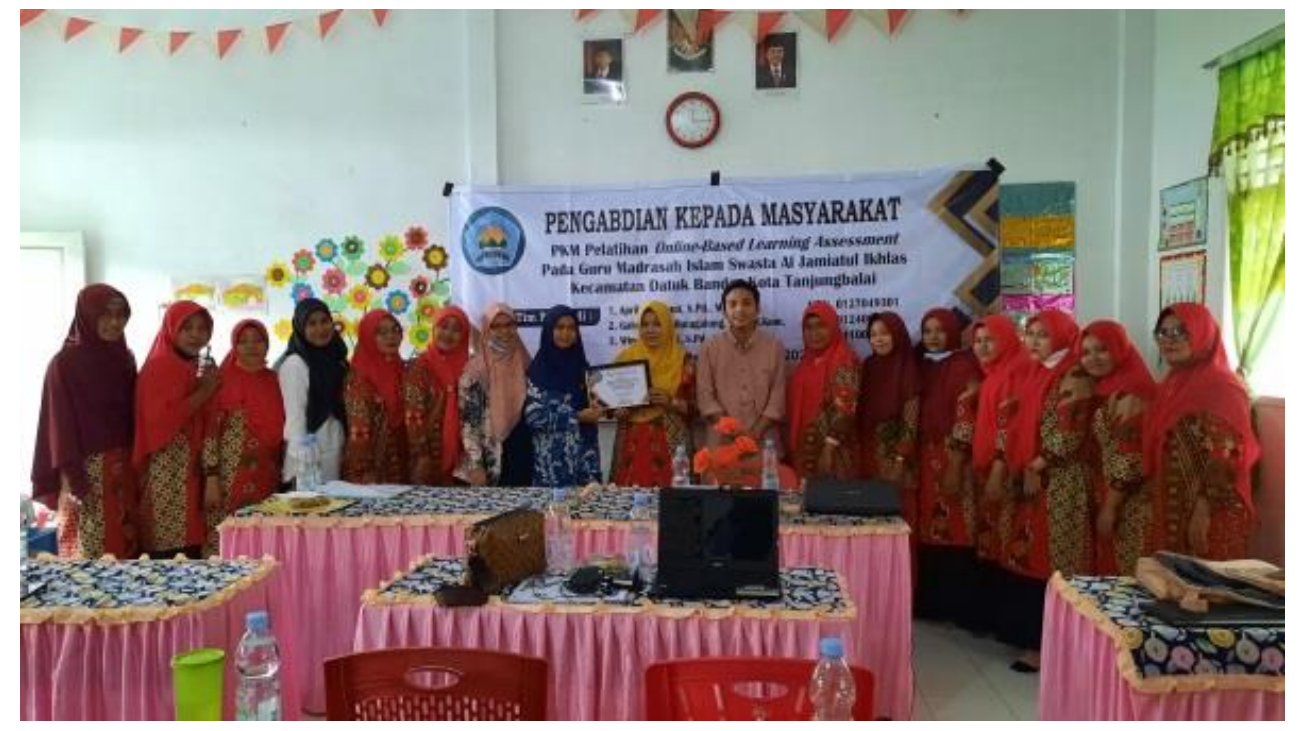

Gambar 2. Foto tim PKM bersama Peserta

Setelah kegiatan pengabdian ini, tim telah mengupayakan agar materi yang disampaikan dapat diterima dan bermanfaat bagi para guru di sekolah mitra dengan memudahkan mereka melakukan asesmen daring menggunakan quizizz dan google form.

Lebih lanjut, hal ini dapat meminimalisir penggunaan kertas sehingga dapat mewujudkan pembelajaran yang green and nature-friendly. Keberlanjutan program ini dapat diukur dengan adanya aktivitas kegiatan lanjutan seperti blended-learning di sekolah mitra.

\section{Kesimpulan}

Kegiatan pengabdian kepada masyarakat ini berupa pelatihan asesmen pada pembelajaran daring menggunakan Quizizz dan Google Form. Mitra sekolah PKM adalah Madrasah Islam Swasta Al Jamiatul Ikhlas Kecamatan Datuk Bandar Kota Tanjungbalai. Kegiatan ini dimulai dengan persiapan, pelaksanaan, monitoring, dan evaluasi. Kegiatan telah dilaksanakan dengan baik dan lancar dimana para peserta mengaku pelatihan ini bermanfaat, sukses dan menarik. Sebagian besar dari mereka sudah bisa menggunakan Quizizz dan Google Form, akan tetapi beberapa peserta saja yang yakin dan optimis untuk menggunakan aplikasi ini setelah pelatihan ini. 


\section{Ucapan Terima Kasih}

Kegiatan pengabdian kepada masyarakat ini dibiayai oleh DIPA Politeknik Negeri Medan, sesuai Surat Perjanjian Pelaksanaan Kegiatan Nomor: B/634/PL5/PM.01.00/2021 dengan tanggal 25 Oktober 2021. Atas dukungan finansial ini, penulis mengucapkan terima.

\section{Daftar Pustaka}

Admin. (2020). Profile MTs A/-Abraar Tandam Hilir I [Online]. Sistem Informasi Aplikasi Pendidikan. http://10213721.siap-sekolah.com/sekolah-profil/

Batubara, H. H., \& Ariany, D. N. (2016). Workshop penggunaan google form sebagai media evaluasi pembelajaran pada dosen-dosen fakultas studi islam. Jurnal Al-Ikhlas, 2(1), 39-44.

Darmaningrat, E. W. T., Ali, A. H. N., \& Prasetianto, R. (2018). Pemanfaatan aplikasi digital learning untuk pembelajaran pengayaan di sekolah menengah kota Surabaya. Prosiding Seminar Nasional Sistem Informasi Indonesia, 85-96.

Dharmawan, K., Ramona, Y., Rupiasih, N., \& Nilakusmawati, D. P. E. (2015). Pemanfaatan aplikasi Google docs sebagai media pembinaan karya ilmiah remaja. Prosiding Seminar Nasional Teknologi Informasi dan Aplikasinya 2015, 5.

Hafid, A., Hayami, R., Fatma, Y., \& Wenando, F. A. (2018). Optimalisasi pemanfaatan google classroom sebagai media pembelajaran di SMK Negeri 1 Bangkinang. Jurnal Pengabdian Untuk Mu NegeRI, 2(1), 17-20.

Ismawan, F., Irfansyah, P., \& Apriyani, D. D. (2018). Pengoptimalan cloud storage-google drive sebagai media pembelajaran untuk guru SMP dan SMA. Jurnal PKM: Pengabdian kepada Masyarakat, 1(1), 61-70. https://doi.org/10.30998/jurnalpkm.v1i01.2362

Jabarnews.com. (2020, March 17). Mulai 18 Maret, Disdik Deli Serdang Tetapkan Libur Sekolah [Online]. https://jabarnews.com/. https://jabarnews.com/read/82824/mulai18-maret-disdik-deli-serdang-tetapkan-libur-sekolah

Maharani, N., \& Kartini, K. S. (2019). Penggunaan google classroom sebagai pengembangan kelas virtual dalam keterampilan pemecahan masalah topik kinematika pada mahasiswa jurusan sistem komputer. PENDIPA Journal of Science Education, 3(3), 167-173. https://doi.org/10.33369/pendipa.3.3.167-173

Sabran, \& Sabara, E. (2018). Keefektifan Google Classroom sebagai media pembelajaran. Prosiding Seminar Nasional Lembaga Penelitian Universitas Negeri Makassar, 122-125.

Wicaksono, V. D., \& Rachmadyanti, P. (2017). Pembelajaran blended learning melalui Google classroom di sekolah dasar. Prosiding Seminar Nasional Pendidikan PGSD UMS \& HDPGSDI Wilayah Jawa, 513-521. 